\title{
Por uma quarentena de direitos para as favelas e as periferias!
}

Pour une quarantaine de droits pour les bidonvilles et les périphéries!

¡Por una cuarentena de derechos para los barrios bajos y las periferias!

For a quarantine of rights for the slums and the peripheries!

\section{Jorge Luiz Barbosa}

\section{(2) OpenEdition}

\section{Journals}

\section{Electronic version}

URL: http://journals.openedition.org/espacoeconomia/10274

DOI: 10.4000/espacoeconomia.10274

ISSN: 2317-7837

\section{Publisher}

Núcleo de Pesquisa Espaço \& Economia

\section{Electronic reference}

Jorge Luiz Barbosa, « Por uma quarentena de direitos para as favelas e as periferias! », Espaço e Economia [Online], 17 | 2020, Online since 06 April 2020, connection on 22 April 2020. URL : http:// journals.openedition.org/espacoeconomia/10274 ; DOI : https://doi.org/10.4000/espacoeconomia. 10274

This text was automatically generated on 22 April 2020.

(c) NUPEE 


\title{
Por uma quarentena de direitos para as favelas e as periferias!
}

\author{
Pour une quarantaine de droits pour les bidonvilles et les périphéries! \\ ¡Por una cuarentena de derechos para los barrios bajos y las periferias! \\ For a quarantine of rights for the slums and the peripheries!
}

Jorge Luiz Barbosa

1 Estamos em março, próximos de completar o primeiro mês das primeiras notificações de pessoas contaminadas pelo CoVID-19 no Brasil. Como sabemos, China e Itália se tornaram, por motivos próprios, as situações mais graves e reportadas da epidemia. $\mathrm{Na}$ sequência imediata da expansão geográfica do COVID - 19, países do continente asiático como Indonésia, Singapura, Japão e Coréia do Sul começaram a ser afetados, assim como países europeus e os Estados Unidos já identificam a alta progressão de contágios e vítimas fatais. Em fevereiro o vírus atravessa oceanos e céus chega à América Latina, particularmente, em nosso país. Hoje são mais de 250 mil contagiados no mundo!

Ebola e H1N1 já haviam feito seus ensaios de uma extensão mundializada, felizmente foram contidos. Todavia, é o coronavírus que alcança o título de pandemia, ou de epidemia global. Não só pelo modo veloz que se expande e contamina populações de vários países, mas também pelo o seu vetor urbano de extensão: as cidades globais.

Filmes de ficção científica foram pródigos ao colocar nas telas do cinema diversos cenários catastróficos de epidemias bacteriológicas e viróticas. Em um deles, de 1996, Os Doze Macacos de Terry Gilliam, o planeta sofreu uma devastação demográfica devido a um vírus letal que se espalhou pelas grandes cidades do mundo. É desta cena apocalíptica que um presidiário é enviado ao passado (em troca de sua liberdade) para encontrar a fonte e o autor da contaminação e assim mudar a história. Dizem que a ficção imita a vida. Porém, ainda não podemos ir ao passado mais distante para rever e mudar o processo urbanização marcado pelas desigualdades sociais e degradação da natureza que estão no cerne de nossas crises sociais, culturais e ambientais. Nem mesmo voltar ao passado mais recente para reparar as políticas neoliberais que nos tomaram os direitos ao trabalho, à habitação digna, à natureza e à saúde. Por outro 
lado, por mais do que sejam severas as críticas presentes nas narrativas estéticas sobre o tema, ver também Contágio (2011) de Steven Soderbergh, nenhum dos filmes de ficção sobre o tema (inclusive devido a sua matriz norte-americana e europeia de produção) elegeram as sociedades moderno-coloniais como sua referência.

Então, não podemos contar com ficção para vislumbrar o que pode ou não poderá nos aterrorizar ou nos acalentar. Só nos resta trazer o mundo da vida, que não é ficção, para centro de nossas preocupações e inconformidades. É isso, trazer a dramática, ou melhor, a trágica situação para nossa condição de humanidade urbana, hoje tão marcada pelas desigualdades sociais, raciais e étnicas, como a brasileira. Se do Príncipe de Mônaco ao funcionário de operações do metrô de São Paulo - passando por senadores, generais, professores, empregadas domésticas - todos possam sofrer com a contaminação do vírus, é preciso reparar as condições de atenção, proteção e cuidados aos homens e mulheres mais vulneráveis, não só por conta da idade ou de um histórico de saúde, mas sim de sua condição social de corpo e território.

5 Enfim, estamos no Brasil. Em 20 dias temos mais contaminados do que nos 20 dias da Itália. Nossas duas maiores cidades - Rio de Janeiro e São Paulo - já apresentam um número crescente de pessoas com testes positivos para Covid-19. Diante das limitações previsíveis de atendimento hospitalar, da impossibilidade de uma vacina e até mesmo da limitação de recursos para identificação da contaminação das pessoas, a alternativa tem sido evitar ao máximo a propagação do vírus. Para isso, o isolamento social vem sendo uma recomendação obrigatória e talvez a mais eficaz para o quadro de progressão geométrica da contaminação virótica.

6 Ficar em casa. Reduzir contatos pessoais. Exercer o trabalho remoto. Não circular pelas ruas. Não frequentar bares e restaurantes. Fechar escolas, universidades e os estádios de futebol. Proteger a si e aos seus familiares do contágio imediato é, sem dúvida, um recurso para muitos, porém não para todos. Há trabalhadoras e trabalhadores cujas condições sociais e urbanas são por demais vulnerabilizadoras, de seus corpos e territórios, para os quais nem a ficção científica é convocada para coloca-los em cena.

7 São pessoas que circulam pouco pela cidade, mas as pessoas da cidade circulam por elas. São trabalhadores e trabalhadoras em supermercados, motoristas de ônibus e vans, vendedores e vendedoras em trens, entregadores em suas bicicletas e motocicletas, atendentes em lojas e ambulantes no comércio de rua (...) em situação de desproteção às exposições ao contágio e, evidentemente, a transmissão para outros, inclusive seus familiares. Como coloca-las em quarentena preventiva em suas casas se as relações de trabalho em precarização de vínculos formais e o desemprego estrutural as empurram cada vez mais para o abismo da desigualdade e, agora, para a vulnerabilidade ao coronavírus. Essas pessoas aqui identificadas como vulneráveis à epidemia global residem, em sua expressiva maioria, em favelas e periferias de nossas metrópoles, cujas condições urbanas de saneamento e de equipamentos de saúde pública estão longe de adequadas às demandas regulares. Com esse cenário assustador das consequências dos agravos à saúde provocados com o coronavírus teremos uma experiência trágica anunciada pela frente. Acrescido de que favelas e periferias do Rio de Janeiro e São Paulo, metrópoles com crescimento de pessoas contaminadas, há incidências já historicamente notificadas de doenças respiratórias (tuberculose, bronquite, asma, gripes) em função da exposição a viroses e as condições socioambientais de suas moradas. Portanto, há uma condição relacional de corpoterritório da qual não podemos deixar de trazer para atenção pública, inclusive 
reafirmando a expressão racial dessa composição, uma vez que os trabalhadores mais expostos / moradores de favelas e periferias são expressivamente negros e negras.

o cenário não é de altíssimo risco, mas sim de altíssima evidência. Para tanto, é preciso que o Estado seja republicano na tragédia. Há exigibilidade de ações e investimentos urgentes para a proteção e o cuidado das pessoas em geral. Todavia, não se pode perder a dimensão da fragilidade imediata e evidente da relação corpo-território como chave de políticas emergenciais e estratégicas de garantia de direitos à vida por parte do Estado. As favelas e periferias precisam de uma quarentena imediata de serviços, bens, equipamentos e renda que permita enfrentar o contágio em série que as ameaça gravemente.

Para tanto, as organizações da sociedade civil, profissionais de saúde e movimentos sociais populares precisam ser reconhecidos e afirmados como atores fundamentais para criação de uma ampla agenda de proteção e cuidados às populações e territórios mais vulneráveis aos danos (im)previsíveis da propagação do coronavírus. Essa agenda é urgente, assim como é a mobilização da solidariedade não só entre familiares e amigos, mas entre vizinhos, entre colegas de trabalho, entre pessoas que estão próximas e/ou distantes. São solidariedades horizontais que sempre se fizeram presentes no cotidiano das favelas e periferias e, agora, serão por demais decisivas para superar a tragédia que se avizinha. Vale lembrar, afinal, que em situações limites com a qual estamos lidando a Democracia ganha o sentido explícito de garantia do Direito à Vida.

\section{ABSTRACTS}

Coronavirus epidemic has progressed in several society with dramatic and frightening impacts. As we are all are in high risk of contamination. However, the most vulnerable are men and women whose bodies and territories are most exposed to the pandemic, mainly due to the profoundly unequal conditions of its existence in our cities. Urgently, is necessary a quarantine of rights for the slums and the peripheries.

A epidemia do coronavírus ganhou uma progressão diversas sociedades com impactos dramáticos e assustadores. Sabemos que todos nós estamos em situação altíssimo risco de contaminação. Entretanto, os mais vulneráveis são homens e mulheres cujos corpos e territórios estão mais expostos à pandemia, sobretudo devido às condições profundamente desiguais de sua existência em nossas cidades. É preciso, urgentemente, uma quarentena de direitos para as favelas e periferias!

Les effets de la pandémie de la Covid-19 sont déjà si effrayantes que dramatiques. Même si toutes les personnes sont en risque, les plus vulnérables sont ceux dont les corps et les territoires se situent dans les bidonvilles et les périphéries. A cause de la profonde inégalité urbaine, il faut proclamer l'urgence d'une quarantaine de droits pour les plus vulnérables.

La epidemia de coronavirus ha progresado en varias sociedades con impactos dramáticos y aterradores. Sabemos que todos corremos un riesgo muy alto de contaminación. Sin embargo, los 
más vulnerables son hombres y mujeres cuyos cuerpos y territorios están más expuestos a la pandemia, principalmente debido a las condiciones profundamente desiguales de su existencia en nuestras ciudades. ¡Hay una necesidad urgente de una cuarentena de derechos para barrios marginales y periferias!

INDEX

Palavras-chave: Covid-19, vulnerabilidade, favelas, periferia, Brasil

Keywords: Covid-19; vulnerability; slums, peripheries, Brazil

Mots-clés: Covid-19, vulnérabilité, bidonvilles, périphéries, Brésil

AUTHOR

JORGE LUIZ BARBOSA

Professor da Universidade Federal Fluminense

Fundador do Observatório de Favelas 